\title{
A study evaluating third trimester haemoglobin level as a predictor of feto-maternal outcome in pregnancy induced hypertension cases
}

\author{
Sasmita Das, Tapan Pattanaik*, Manisha Sahu
}

Department of Obstetrics and Gynecology, IMS and SUM Hospital, Under Siksha 'O' Anusandhan University, Bhubaneswar, Odisha, India

Received: 13 August 2018

Accepted: 06 September 2018

\section{*Correspondence:}

Dr. Tapan Pattanaik,

E-mail: drtapan73@gmail.com

Copyright: (c) the author(s), publisher and licensee Medip Academy. This is an open-access article distributed under the terms of the Creative Commons Attribution Non-Commercial License, which permits unrestricted non-commercial use, distribution, and reproduction in any medium, provided the original work is properly cited.

\section{ABSTRACT}

Background: The aim of this study is to assess whether third trimester haemoglobin level can be used as a predictor of feto-maternal adverse outcomes in pregnancies complicated with PIH.

Methods: This is an observational study in the Obstetrics and Gynaecology Department of IMS and SUM hospital, SOA university from July 2015 to December 2017. Institutional ethical committee permission obtained. All singleton pregnancies delivered during this period with PIH were included in the study. PIH and eclampsia was diagnosed as per ISSHP criteria. All chronic hypertension cases excluded. All were evaluated with haemoglobin level. They were divided into 3 groups depending upon haemoglobin level; low $(<11 \mathrm{gm} \%)$, normal $(11-13 \mathrm{gm} \%)$ and high haemoglobin group (>13gm\%) considering the WHO standard. Maternal complications observed were incidence of eclampsia, abruptio placentae, HELLP syndrome, PPH, neurological complications, ICU admissions and death. Fetal outcomes studied were NICU admission, stillbirth, incidence of prematurity and low birth weight. All these parameters were compared among 3 groups. Statistical analysis was done with SPSS 20 software using Yate's corrected chi square test.

Results: Incidence of eclampsia was significantly greater with both high $(\mathrm{p}<0.001)$ and low $(\mathrm{p}=0.0085)$ haemoglobin level than normal haemoglobin level. Maternal complications and adverse perinatal outcomes (stillbirth, low birth weight, prematurity, NICU admission) are significantly greater with high haemoglobin level than cases with normal haemoglobin level. There is no significant difference in maternal and perinatal complications between low and normal haemoglobin group.

Conclusions: High haemoglobin level $>13 \mathrm{gm} \%$ in third trimester is associated with worst feto-maternal outcome whereas normal haemoglobin level $(11-13 \mathrm{gm} \%)$ is associated with least feto-maternal complications.

Keywords: Haemoglobin, HELLP syndrome, NICU admission, Pregnancy induced hypertension, Stillbirth

\section{INTRODUCTION}

Plasma volume increases by $40 \%$ above pre-pregnancy level in normal pregnancy. Maximum haemodilution is achieved at around 30 weeks, followed by small decrease of haemodilution at term. ${ }^{1}$ But, red cell mass increases in a linear fashion with gestation and increase restricted to $25-30 \%$ at term. ${ }^{2}$ This physiological hemo-dilution prepares a low viscosity and low resistance intravascular system which allows an optimal red cell circulation in the low-velocity placental circulation. ${ }^{3}$ A high haemoglobin concentration during second trimester could be due to ineffective plasma volume expansion or enhanced erythropoiesis as a compensatory mechanism to impaired oxygenation in placenta. ${ }^{4,5}$

Earlier researches document haemoconcentration with hypovolemia due to ineffective plasma volume expansion 
is a feature of pre-eclampsia. A high booking haemoglobin is significantly associated with preeclampsia. ${ }^{5}$ Both high haemoglobin $(>13.2 \mathrm{gm} / \mathrm{dl})$ and low haemoglobin $(<10.4 \mathrm{gm} / \mathrm{dl})$ are associated with adverse perinatal outcome (preterm delivery, low birth weight, perinatal mortality) in pregnancies not complicated with PIH. ${ }^{6}$

Maternal anaemia is known for adverse maternal and perinatal outcome like postpartum haemorrhage, prematurity, intra uterine growth restriction and low birth weight babies. ${ }^{7,8}$ Not only high haemoglobin, severe anaemia is also associated with a greater risk of preeclampsia. ${ }^{9}$ Risk of adverse outcome in pregnancy is lowest at mid-trimester mean haemoglobin of 11-12gm $/ \mathrm{dl}^{10}$

Relationship of maternal haemoglobin concentration to maternal and perinatal outcome in a subset of women with PIH has not been observed in many studies. Aim of present study is to find out the relation of haemoglobin level in third trimester with maternal and perinatal outcome in PIH patients. To know, whether third trimester haemoglobin level helps to indicate adverse outcomes in $\mathrm{PIH}$ patients.

\section{METHODS}

This is an observational study in the Department of Obstetrics and Gynaecology of IMS and SUM hospital, SOA university from July 2015 to December 2017.

\section{Inclusion criteria}

311 consecutive patients with singleton pregnancy admitted to in patient department or delivery room with pregnancy induced hypertension were included in the study.

PIH was diagnosed when the systolic blood pressure was $\geq 140 \mathrm{mmHg}$ and/or diastolic blood pressure $\geq 90 \mathrm{mmHg}$ measured on 2 occasions 4-6 hours apart beyond 20 weeks of pregnancy. Cases of PIH with convulsion are considered as cases of eclampsia. ${ }^{11}$

\section{Exclusion criteria}

Cases of chronic hypertension like essential hypertension, chronic renal disease, connective tissue disorder were excluded.

Haemoglobin estimation was done for all cases during admission. Haemoglobin estimation in present institute is done by cyanide free Sodium Lauryl Sulphate method, which was uniform in all present cases. All the cases were divided into 3 groups; low haemoglobin group (<11gm\%), normal haemoglobin group (11-13gm\%) and high haemoglobin group $(>13 \mathrm{gm} \%)$ considering the WHO standard.
Investigations and management were done according to hospital protocol. All cases were evaluated with blood investigations like haemoglobin estimation, platelet count, liver function tests, renal function tests. Coagulation profile (PT, aPTT, INR) was evaluated in clinically suspected cases of abruption, HELLP syndrome, disseminated intravascular coagulation (DIC) patients. Urine protein estimation was done by dipstick method. Obstetric ultrasound with Doppler velocimetry was performed in preterm PIH where decision to continue pregnancy for some period was decided. Admission cardiotocography was performed in all cases.

All cases of acute severe hypertension (systolic $\geq 160 \mathrm{mmHg}$, diastolic $\geq 110 \mathrm{mmHg}$ ) were treated with intravenous labetolol preferably or oral labetolol/ nifedipine. Any hypertension diastolic $\geq 100 \mathrm{mmHg}$ was treated with oral labetolol/ nifedipine to maintain blood pressure in normal range. All cases of eclampsia, imminent eclampsia (with features like severe headache, visual scotomata, nausea, vomiting, oliguria, epigastric pain) and severe hypertension were treated with magnesium sulphate by Pritchard's regime. Betamethasone $12 \mathrm{mg}$, 24 hours apart administered to all pregnancies less than 37 weeks if imminent delivery is not indicated.

All cases beyond 37 weeks of gestation were planned for delivery. Preterm pregnancies were offered conservative management with the investigations mentioned above twice a week except in cases of eclampsia, imminent eclampsia, uncontrolled maternal hypertension despite antihypertensives, HELLP syndrome, placental abruption, reverse end diastolic flow in Doppler velocimetry, non-reassuring CTG, still birth. Blood pressure monitoring was done 4 hourly for those on conservative management.

All the patients were observed for maternal outcomes like incidence of eclampsia, complications like abruptio placentae, HELLP syndrome, postpartum haemorrhage (PPH), neurological complications, intensive care unit (ICU) admission and maternal death. Fetal outcomes studied are described below.

They were described as normal outcome when baby shifted to mother side, neonatal intensive care unit (NICU) admission and stillbirth (delivery of a dead baby after 24 weeks of pregnancy). Incidence of low birth weight $(\mathrm{LBW})(<2.5 \mathrm{~kg})$, incidence of premature birth ( $<37$ weeks) were observed. All these parameters were compared among 3 groups to see any statistically significant difference exists with different haemoglobin status.

\section{Statistical analysis}

Statistical analysis was done with SPSS 20 software using Yate's corrected chi square test. 


\section{RESULTS}

Total 311 patients of PIH were recruited in the study period.273 cases out of $311(87.8 \%)$ had pre-eclampsia, $38(12.2 \%)$ cases had eclampsia. Socio-demographic distribution of patients are described below. All PIH patients divided into 3 categories according to the haemoglobin level. 81 candidates in low haemoglobin $(<11 \mathrm{gm} \%)$ group, 181 in normal haemoglobin (11$13 \mathrm{gm} \%$ ) group and 49 in high haemoglobin (>13gm\%) group. Table 1 shows age distribution of cases according to haemoglobin level.

Table 1: Age distribution of cases.

\begin{tabular}{|lll|l|}
$\begin{array}{l}\text { Age } \\
\text { (years) }\end{array}$ & $\begin{array}{l}\text { Low Hb } \\
(<11 \text { gm } \%)\end{array}$ & $\begin{array}{l}\text { Normal Hb } \\
(11-13 \text { gm } \%)\end{array}$ & $\begin{array}{l}\text { High Hb } \\
(>13 \text { gm } \%) \\
\text { N=49 }\end{array}$ \\
\hline$\leq 20$ & $6(7.4 \%)$ & $11(6.1 \%)$ & $1(2 \%)$ \\
\hline $21-30$ & $64(79 \%)$ & $122(67.4 \%)$ & $35(71.4 \%)$ \\
\hline $31-40$ & $10(12.3 \%)$ & $48(26.5 \%)$ & $13(26.5 \%)$ \\
\hline$>40$ & $1(1.3 \%)$ & 0 & 0 \\
\hline
\end{tabular}

Maximum patients $221 / 311(71.1 \%)$ are in $21-30$ age group. Proportion of patients in this age group is highest in all 3 haemoglobin groups. 64/81 (79\%), 122/181 $(67.4 \%)$ and $35 / 49(71.4 \%)$ in low normal and high haemoglobin group respectively.

Table 2: Parity distribution of cases.

\begin{tabular}{|llll|}
\hline $\begin{array}{l}\text { Study } \\
\text { groups }\end{array}$ & $\begin{array}{l}\text { Low Hb } \\
(<11 \text { gm \% })\end{array}$ & $\begin{array}{l}\text { Normal Hb } \\
(11-13 g m \%)\end{array}$ & $\begin{array}{l}\text { High Hb } \\
(>13 g m \%) \\
\text { N=41 }=\mathbf{1 8 1}\end{array}$ \\
\hline Primigravida & $58(71.6 \%)$ & $113(62.4 \%)$ & $33(67.3 \%)$ \\
\hline Multigravida & $23(28.4 \%)$ & $68(37.6 \%)$ & $16(32.7 \%)$ \\
\hline
\end{tabular}

Among 311 PIH patients, 204 (65.6\%) were primigravidas, 107 (34.4\%) were multigravidas. Table 2 compares parity with haemoglobin level. When normal $\mathrm{Hb}$ group was compared with high $\mathrm{Hb}$ group by chi square test, $\mathrm{p}=0.4680$; which is not significant. When normal $\mathrm{Hb}$ group was compared with low $\mathrm{Hb}$ group, $\mathrm{p}=0.1665$; which is not significant. There is no significant difference between the groups, when parity is compared.

Table 3: Distribution of pre-eclampsia and eclampsia.

\begin{tabular}{|c|c|c|c|}
\hline $\begin{array}{l}\text { Study } \\
\text { groups }\end{array}$ & $\begin{array}{l}\text { Low Hb } \\
(<11 \text { gm \%) } \\
\mathrm{N}=\mathbf{8 1}\end{array}$ & $\begin{array}{l}\text { Normal Hb } \\
(11-13 \mathrm{gm} \%) \\
\mathrm{N}=181\end{array}$ & $\begin{array}{l}\text { High } \mathrm{Hb} \\
(>13 \mathrm{gm} \%) \\
\mathrm{N}=49\end{array}$ \\
\hline Eclampsia & $13(16 \%)$ & $10(5.5 \%)$ & $15(30.6 \%)$ \\
\hline Preeclampsia & $68(85 \%)$ & $171(94.5 \%)$ & $34(69.4 \%)$ \\
\hline
\end{tabular}

Table 3 describes distribution of pre-eclampsia and eclampsia among the study groups with different haemoglobin level. According to table 3, proportion of eclampsia, which is the severe form of disease, is highest in high haemoglobin group. It is lowest in normal haemoglobin group. Comparing incidence of preeclampsia and eclampsia between high and normal haemoglobin group by Fisher's exact test, $\mathrm{p}<0.001$; which is extremely statistically significant. Comparing between normal and low haemoglobin group, $\mathrm{p}=0.0085$, which is significant.

To present observation, incidence of eclampsia is significantly higher in low and high haemoglobin group compared to normal $\mathrm{Hb}$ group.

Table 4: Distribution of maternal complications.

\begin{tabular}{|llll|}
\hline Study groups & $\begin{array}{l}\text { Low Hb } \\
(<11 g m \%) \\
\text { N=81 }\end{array}$ & $\begin{array}{l}\text { Normal Hb } \\
(11-13 g m \%) \\
\text { N=181 }\end{array}$ & $\begin{array}{l}\text { High Hb } \\
(>13 g m \%) \\
\text { N=49 }\end{array}$ \\
\hline $\begin{array}{l}\text { Normal } \\
\text { maternal } \\
\text { outcome }\end{array}$ & $75(92.6 \%)$ & $176(97.3 \%)$ & $39(79.6 \%)$ \\
\hline Complications & $6(7.4 \%)$ & $5(2.7 \%)$ & $10(20.4 \%)$ \\
\hline
\end{tabular}

Table 4 illustrates maternal outcome (normal/ complications) in 3 study groups. Table 4 depicts maternal complications in different haemoglobin groups. When maternal complications were compared by chi square test between high and normal haemoglobin group, $\mathrm{p}=0.0002$, which is highly significant. A higher rate of maternal complications observed in high haemoglobin group than normal haemoglobin group. Contrary, when maternal complications were compared between low haemoglobin and normal haemoglobin group, $\mathrm{p}=0.1944$; which is not significant. Present observation suggests maternal complications are highest with haemoglobin level >13gm\% and lowest with normal haemoglobin (11$13 \mathrm{gm} \%)$.

Table 5: Distribution according to gestational age at delivery.

\begin{tabular}{|llll}
$\begin{array}{l}\text { Study } \\
\text { group }\end{array}$ & $\begin{array}{l}\text { Low Hb } \\
(<11 \text { gm \% })\end{array}$ & $\begin{array}{l}\text { Normal Hb } \\
(11-13 \text { gm } \%)\end{array}$ & $\begin{array}{l}\text { High Hb } \\
(>13 \text { gm } \%)\end{array}$ \\
Preterm & $22(27.2 \%)$ & $46(25.4 \%)$ & $23(46.9 \%)$ \\
\hline Term & $59(72.8 \%)$ & $135(74.6 \%)$ & $26(53.1 \%)$ \\
\hline
\end{tabular}

Table 5 describes proportion of preterm ( $<37$ weeks) and term ( $\geq 37$ weeks) deliveries among 3 study groups. While comparing high haemoglobin and normal haemoglobin group by chi square test, $\mathrm{p}=0.0012$; which is significant. There is no statistical significance between normal and low Hb group $(\mathrm{p}=0.7472)$. Prematurity is significantly raised with a high haemoglobin level $>13 \mathrm{gm} \%$ than normal haemoglobin (11-13gm\%). But, prematurity is not significantly raised in low haemoglobin group, when compared with normal.

Table 6 compares birth weight in different $\mathrm{Hb}$ groups. When high and normal $\mathrm{Hb}$ group were compared by chi square test, $\mathrm{p}=0.0109$; which is significant. LBW neonates between low and normal $\mathrm{Hb}$ is not significant $(\mathrm{p}=0.774)$. LBW neonates are significantly higher with 
high $\mathrm{Hb}$ concentration than normal. But not with anaemia (low $\mathrm{Hb}$ group).

Table 6: Distribution according to birth weight.

\begin{tabular}{|llll|}
\hline Study group & $\begin{array}{l}\text { Low Hb } \\
(<11 \text { gm \% })\end{array}$ & $\begin{array}{l}\text { Normal Hb } \\
(11-13 \text { gm } \%) \\
\text { N=181 }\end{array}$ & $\begin{array}{l}\text { High Hb } \\
(>13 g m \%) \\
\text { N=49 }\end{array}$ \\
\hline $\begin{array}{l}\text { Normal birth } \\
\text { weight } \\
(\geq 2.5 \mathrm{~kg})\end{array}$ & $46(56.8 \%)$ & $107(59.1 \%)$ & $20(40.9 \%)$ \\
\hline $\begin{array}{l}\text { Low birth } \\
\text { weight } \\
(<2.5 \mathrm{~kg})\end{array}$ & $35(43.2 \%)$ & $74(40.9 \%)$ & $29(59.1 \%)$ \\
\hline
\end{tabular}

Table 7 compares perinatal outcome among 3 study groups. Comparing perinatal outcome in high and normal $\mathrm{Hb}$ group by chi square test, $\mathrm{p}=0.0006$, which is significant. There is no statistically significant difference between low and normal $\mathrm{Hb}$ group $(\mathrm{p}=0.3312)$. Again, worst perinatal outcome in terms of still birth and NICU admission is associated with high haemoglobin level, not with anaemia.

Table 7: Perinatal outcome (normal outcome, stillbirth, NICU admission) among 3 study groups.

\begin{tabular}{|llll|}
\hline $\begin{array}{l}\text { Study } \\
\text { group }\end{array}$ & $\begin{array}{l}\text { Low Hb } \\
(<11 \text { gm } \%)\end{array}$ & $\begin{array}{l}\text { Normal Hb } \\
(11-13 \text { gm } \%)\end{array}$ & $\begin{array}{l}\text { High Hb } \\
\text { N=13gm\%) } \\
\text { N=49 }\end{array}$ \\
\hline $\begin{array}{l}\text { Normal } \\
\text { outcome }\end{array}$ & $57(70.3 \%)$ & $142(78.4 \%)$ & $26(53.1 \%)$ \\
\hline $\begin{array}{l}\text { NICU } \\
\text { admission }\end{array}$ & $18(22.2 \%)$ & $26(14.3 \%)$ & $14(28.6 \%)$ \\
\hline Stillbirth & $6(7.4 \%)$ & $13(7.1 \%)$ & $9(18.3 \%)$ \\
\hline
\end{tabular}

\section{DISCUSSION}

Pregnancy induced hypertension is still one of the important causes of maternal and perinatal morbidity and mortality. Hypertensive disorders complicate 5-10\% pregnancies globally. ${ }^{12}$ Incidence of hypertensive disorders in India is found to be $10.08 \%$ as per national eclampsia registry. ${ }^{13}$ Though not preventable completely, identifying cases early and recognising the group prone for serious complications can help reducing maternal and fetal adverse outcomes.

Both high level of maternal haemoglobin and anaemia are associated with PIH. ${ }^{6} 9$ In established preeclampsia, increased capillary permeability and loss of serum protein results in decreased intravascular volume. ${ }^{14}$ Decreased plasma volume gives rise to increase in maternal haemoglobin concentration. ${ }^{15}$ In pregnancies not complicated with $\mathrm{PIH}$, maternal haemoglobin level correlates with adverse maternal and perinatal outcome. ${ }^{6,7,10}$ In present study, authors are observing any correlation of haemoglobin level in third trimester in PIH patients with maternal and fetal adverse outcomes.
In present observation, incidence of eclampsia, the severe form of disease is significantly greater in high and low haemoglobin group compared to normal $\mathrm{Hb}$ group. A stronger association of eclampsia exists with haemoglobin $>13 \mathrm{gm} \%$. Abnormally high maternal haemoglobin before delivery is associated with placental dysfunction due to high viscosity of blood. Placental ischemia leads to release of placental factors which promotes erythropoiesis. Haemoconcentration initiates peri villous fibrin deposit and placental infarction. A vicious cycle of hypoxia-ischemia- infarction continues which worsens the disease process. ${ }^{16}$ Exact reason of raised incidence of eclampsia is not mentioned in studies, probably relates to cerebral hypoxia owing to haemoconcentration, vasoconstriction and cerebral oedema. Significantly higher mean haematocrit value was observed in preeclampsia than normal pregnancy in a cross-sectional study. Statistically significant difference existed between mild and severe PIH as well. ${ }^{17}$

Prevalence of preeclampsia and eclampsia is significantly higher in women with severe anemia with $\mathrm{Hb}$ concentration $<7 \mathrm{gm} / \mathrm{dl}^{7}{ }^{7}$ The susceptibility of pregnant women with anaemia to PIH may be due to antioxidant and micronutrient deficiency. Reduced serum levels of calcium, magnesium and zinc are possible contributors. In present study, though authors have not categorized anaemic mothers into mild, moderate and severe disease, incidence of eclampsia is significantly higher with low haemoglobin level than normal.

Maternal complications are significantly greater in high haemoglobin group than normal haemoglobin group $(\mathrm{p}=0.002)$. There is no significant difference between low and normal haemoglobin group. Authors could not find studies correlating $\mathrm{Hb}$ level in PIH with maternal outcome. Out of 10 cases of complication in high $\mathrm{Hb}$ group, 3 were cases of HELLP syndrome, 3 cases of $\mathrm{PPH}, 3$ cases of neurological complications and one case of maternal death after status eclampticus. 4 cases needed ICU admission among these ( 2 cases of HELLP syndrome and 2 cases with neurological complication). Low and normal haemoglobin group contain all 6 cases of abruption, 2 cases of HELLP syndrome, 1 case of PPH, 2 cases of neurological complication. Anemia could be the effect of abruptio placentae than the cause. So, it is the high maternal haemoglobin (a state of haemoconcentration and resultant hypoxia) is correlated with most of the complications. Prematurity and low birth weight neonates are significantly higher in high haemoglobin group than normal haemoglobin group. There is no statistical difference between low and normal haemoglobin group. Similar findings observed in other studies where maternal hemoglobin concentration is inversely proportional to birth weight percentile in PIH. ${ }^{18,19}$ In a study by Sagen $\mathrm{N}$ et al, the last maternal haemoglobin concentration before delivery was correlated with perinatal outcome. Abnormally high $\mathrm{Hb}$ was associated with placental dysfunction, intrauterine 
fetal growth restriction, perinatal distress and higher rate of perinatal death. ${ }^{19}$

Mean maternal haemoglobin concentration between 11.0 and $12 \mathrm{gm} / \mathrm{dl}$ in $2^{\text {nd }}$ trimester had lowest risk of any adverse perinatal outcome. A possibility of adverse event was highest between haemoglobin $13.0-15 \mathrm{gm} / \mathrm{dl} .{ }^{10}$ Low birth weight, perinatal mortality, and prematurity were significantly higher in cases where mid trimester $\mathrm{Hb}$ was more than $13.2 \mathrm{gm} / \mathrm{dl}{ }^{6}$ Authors could not find any statistical significance between low and normal Hb group when considered for perinatal outcomes. Lowest incidence of low birth weight and preterm labour was associated with haemoglobin concentration $95-105 \mathrm{gm} / \mathrm{L}$ which can be considered as low $\mathrm{Hb}$ according to WHO standard. ${ }^{3}$ In a large prospective European study, perinatal mortality was lowest with a haemoglobin range of $9-11 \mathrm{gm} / \mathrm{dl}$ in first antenatal checkup. ${ }^{20} \mathrm{U}$-shaped curve of increased risk by haemoglobin level for adverse birth outcomes (stillbirths, preterm deliveries, SGA) was observed in another study. The optimal haemoglobin level, with the lowest perinatal risk, was between 11 and $13 \mathrm{~g} / \mathrm{dl} .^{21}$ High haemoglobin at first antenatal visit $(>14.6 \mathrm{gm} \%)$ is associated with increased risk of still birth according to a population based Swedish study. ${ }^{22}$

\section{CONCLUSION}

Pregnancy induced hypertension is associated with adverse maternal and perinatal outcomes. Early detection, segregation of cases prone for worst outcome and timely proper intervention can improve the outcomes.

From present study, it is clear that haemoglobin measurement in third trimester in PIH patients can be used as an indicator of maternal and fetal adverse outcomes.

Normal haemoglobin level between 11 and $13 \mathrm{gm} \%$ is associated with least maternal complications like eclampsia, maternal morbidity and mortality. Fetal complications like prematurity, low birth weight, NICU admission, stillbirth rate were lowest with this haemoglobin level.

Worst maternal and fetal outcomes are associated with haemoglobin level more than $13 \mathrm{gm} \%$. Anaemic mothers $(\mathrm{Hb}<11 \mathrm{gm} \%)$ are prone to moderate level of maternal and fetal complications between high and normal haemoglobin.

Haemoglobin level is performed in all present obstetric cases as part of routine investigation. Without increasing the cost or burden on health care, it can be used as an indicator of adverse feto-maternal outcome.

Funding: No funding sources

Conflict of interest: None declared

Ethical approval: The study was approved by the Institutional Ethics Committee

\section{REFERENCES}

1. Hytten FE, Paintin DB. Increase in plasma volume during normal pregnancy. BJOG: Int $\mathrm{J}$ Obstet Gynaecol. 1963;70(3):402-7.

2. Taylor DJ, Lind T. Red cell mass during and after normal pregnancy. BJOG: Int J Obstet Gynaecol. 1979;86(5):364-70.

3. Steer PJ. Maternal hemoglobin concentration and birth weight. Am J Clinic Nutr. 2000;71(5):1285S$7 \mathrm{~S}$.

4. Rosso P, Donoso E, Braun S, Espinoza R, Fernadez C, Salas SP. Maternal hemodynamic adjustment in idio- pathic fetal growth retardation. Gynecol Obstet Invest. 1993;35:162-5.

5. Ortner A, Zech H, Humpeler E, Mairbaeurl H. May high oxygen affinity of maternal hemoglobin cause fetal growth retardation?. Gynecol. 1983;234:79-85.

6. Murphy JF, Newcombe RG, O'riordan J, Coles EC, Pearson JF. Relation of haemoglobin levels in first and second trimesters to outcome of pregnancy. Lancet. 1986;327(8488):992-5.

7. Nair M, Choudhury MK, Choudhury SS, Kakoty SD, Sarma UC, Webster P, et al. Association between maternal anaemia and pregnancy outcomes: a cohort study in Assam, India. BMJ Global Health. 2016;1(1):e000026.

8. Anjanappa B, Radhika BH, Nataraja HG, Ramaiah R, Sathya P. Maternal haemoglobin and perinatal outcome. Int J Reprod Contracept Obstet Gynecol. 2017;4(5):1335-8.

9. Ali AA, Rayis DA, Abdallah TM, Elbashir MI, Adam I. Severe anaemia is associated with a higher risk for preeclampsia and poor perinatal outcomes in Kassala hospital, eastern Sudan. BMC Res Notes. 2011;4(1):311.

10. von Tempelhoff GF, Heilmann L, Rudig L, Pollow K, Hommel G, Koscielny J. Mean maternal secondtrimester hemoglobin concentration and outcome of pregnancy: a population-based study. Clinic Applied Thrombosis/Hemostasis. 2008;14(1):19-28.

11. Tranquilli AL, Dekker G, Magee L, Roberts J, Sibai BM, Steyn W, et al. The classification, diagnosis and management of the hypertensive disorders of pregnancy: a revised statement from the ISSHP. Pregnancy Hypertension. 2014;4(2):97-104.

12. Zenebe W, Hailemariam S, Mirkuzie W. Hypertensive disorders of pregnancy in Jimma University specialized hospital. Ethiop J Health Sci. 2011;21(3):147-54.

13. Sanjay G, Girija W. Preeclampsia-eclampsia. Obstet Gynecol. 2014;64(1):4-13.

14. Chappel LL, Bewley S. Pre-eclamptic toxaemia: the role of uterine artery Doppler. Br J Obstet Gynaecol. 1998;105:379-82.

15. Walker JJ. Pre-eclampsia. Lancet. 2000;356:1260-5.

16. Sagen N, Koller O, Haram K. Haemoconcentration in severe pre-eclampsia. $\mathrm{Br} \mathrm{J}$ Obstet Gynaecol. 1982;89(10):802-5. 
17. Basak SK, Begum K, Rashid M, Yasmin N, Begum H. Haematocrit Value in Preeclampsia. Bangladesh J Obstet Gynaecol. 2015;30(2):80-5.

18. Amburgey ÖA, Ing E, Badger GJ, Bernstein IM. Maternal hemoglobin concentration and its association with birth weight in newborns of mothers with preeclampsia. J Maternal-Fetal Neonatal Med. 2009;22(9):740-4.

19. Sagen N, Koller O, Haram K. Haemoconcentration in severe pre-eclampsia. BJOG: Int $\mathbf{J}$ Obstet Gynaecol. 1982;89(10):802-5.

20. Little MP1, Brocard P, Elliott P, Steer PJ. Hemoglobin concentration in pregnancy and perinatal mortality: a London-based cohort study. Am J Obstet Gynecol. 2005;193(1):220-6.
21. Gonzales GF, Steenland K, Tapia V. Maternal hemoglobin level and fetal outcome at low and high altitudes. Am J Physiol-Regulatory Integrat Comparat Physiol. 2009;297(5):R1477-85.

22. Stephansson O, Dickman PW, Johansson A, Cnattingius S. Maternal hemoglobin concentration during pregnancy and risk of stillbirth. JAMA. 2000;284(20):2611-7.

Cite this article as: Das S, Pattanaik T, Sahu M. A study evaluating third trimester haemoglobin level as a predictor of feto-maternal outcome in pregnancy induced hypertension cases. Int J Reprod Contracept Obstet Gynecol 2018;7:4439-44. 